\title{
Globalização, Cultura e Subjetividade: Discussão a Partir dos Meio de Comunicação de Massa'
}

\author{
Deise Mancebo ${ }^{2}$ \\ Universidade do Estado do Rio de Janeiro
}

\begin{abstract}
RESUMO - O artigo analisa o cenário da cultura global, com especial destaque à indústria cultural, visando a uma compreensão mais cuidadosa sobre a formação dos sujeitos no contexto contemporâneo. Apresenta parte da produção teórica sobre os meios de comunicação de massa, estabelecendo paralelos entre a discussão frankfurtiana, os estudos culturais e os que enfatizam a cultura no cotidiano. Analisa alguns embates que se definem nesse campo de estudos, com destaque à tensão entre homogeneização e diferenciação cultural, estabelecendo um diálogo desta temática com a produção de subjetividades no contexto global. Conclui apresentando a globalização como um fenômeno múltiplo, que pode levar a caminhos bem diversos, nos quais são localizáveis, desde os apelos ao universalismo cultural, que remeteriam a uma inclusão homogeneizadora; até diversos tipos de resistência a esse processo, com a formação de grupos identitários, movimentos xenófobos e até apropriações criativas desenvolvidas por grupos de cidadãos.
\end{abstract}

Palavras-chave: globalização; cultura; subjetividade; meios de comunicação.

\section{Globalization, Culture and Subjectivity: A Discussion About Mass Media}

\begin{abstract}
The article analyzes the scenery of the global culture, with special prominence to the mass media, seeking to a more careful understanding about the formation of the subjects in the contemporary context. It presents part of the theoretical production on the mass media, establishing parallel among the frankfurtian discussion, the cultural studies and the ones that emphasize the culture in the daily. It analyzes some themes in that field of studies, with prominence to the tension between homogenization and cultural differentiation, establishing a dialogue of this theme with the production of subjectivities in the global context. It concludes presenting the globalization as a multiple phenomenon, that can take us to very several destinations, where we can locate the appeals to the cultural universalism, that it would send to an inclusion that homogenize; several resistance types to that process, with the formation of identity groups, xenophobes movements and even creative appropriations developed by citizens' groups.
\end{abstract}

Key words: globalization; culture; subjectivity; mass media.

O processo de globalização abrange uma variedade de fenômenos, tem gerado impactos diferenciados em diversas áreas - econômico-financeira, comercial, cultural, social, dentre outras -, mostra-se atravessado por um certo grau de ambivalência ou imprecisão, revelando-se como uma configuração histórica altamente contraditória. Há uma diversidade de esforços de conceituação e leitura por autores de diferentes áreas sobre o processo global. Porém, pode-se afirmar que existe um elevado consenso, entre eles, de se estar diante de uma nova era do capitalismo e que, no século XX, - mais precisamente, nos últimos 30 anos - o mundo entrou no ciclo de uma história global (Mancebo, 2000).

A transformação da cultura - a "globalização cultural" tem se apresentado como uma estratégia central de garantia desta "nova" ordem, evocando, por um lado, imagens que fazem alusão à homogeneidade e integração mundial, ao mesmo tempo que outras análises destacam os antagonis-

1 Texto baseado em pesquisa com apoio do CNPq, UERJ e FAPERJ, contando com a colaboração de bolsistas de iniciação científica (Ana Paula de Almeida Pereira e Monica Silva da Costa)

2 Endereço: Rua Barão de Cotegipe 416 Casa 7, Vila Isabel, Rio de Janeiro, CEP: 20560-080 - E-mail: mancebo@uerj.br mos, diferenciações e contradições provocadas pela mundialização da cultura.

Toda esta discussão é atravessada por algumas questões. Primeiramente, pelo fato de que, no atual contexto, se assiste a uma certa fusão entre cultura e economia (Jameson, 2001). Assim, a cultura não pode mais ser vista como uma seara onde os homens se refugiariam dos efeitos do capital, ao contrário, é uma das suas mais perfeitas expressões e "o capitalismo tardio depende para seu bom funcionamento de uma lógica cultural, de uma sociedade de imagens voltadas para o consumo" (Cevasco, 2000). Pode-se dizer, inclusive, que se assiste, na atual conjuntura, a uma des-diferenciação desses campos, na medida em que a economia acaba por coincidir com a cultura, fazendo com que até a alta especulação financeira se torne cultural, ao mesmo tempo em que a cultura se torna profundamente orientada para a produção de mercadorias, qual seja, torna-se econômica. Deste modo, é preciso tratar da seara cultural articulada às análises econômicas e sociológicas e mesmo a proposta multicultural, a par das fertilidades que trouxe às discussões sobre a temática, deve ser tomada de forma cautelosa, principalmente as teorizações que entendem as culturas como fundamentalmente divergentes umas das outras, que as apresentam como 
forças autônomas em relação às demais ou às outras esferas da sociedade, especialmente a econômica, desprezando as forças da assimilação e da integração cultural.

Em segundo lugar, é preciso relevar que em meio a tanta diversidade, ambigüidades e mudanças provocadas pelo processo da globalização, e diante das transformações culturais velozes, promovidas, dentre outros aspectos, pela instantaneidade dos avançados meios de comunicação atuais, verificase que as identidades culturais não passam imunes. É importante destacar que se alteram, percorrem um complexo processo de redefinições em diferentes níveis, açambarcando diretamente os sujeitos envolvidos. Nessas circunstâncias, há um certo consenso nas diversas análises, que aponta para o fato das subjetividades contemporâneas se apresentarem fortemente afetadas pelas mudanças globais na esfera cultural.

Baseado nesses pressupostos, este artigo propõe-se à análise do cenário da cultura global, com especial destaque à indústria cultural, visando a uma compreensão mais cuidadosa sobre a formação dos sujeitos no contexto contemporâneo.

\section{Meio de Comunicação de Massa: Definições Preliminares}

Inicialmente, algumas questões terminológicas e teóricas precisam ser definidas. A própria expressão "indústria cultural" é semanticamente carregada. Ela foi cunhada por um projeto analítico que visava denunciar as práticas totalitárias e massificadoras a que se submetia a população e que analisarei um pouco mais à frente. Outra expressão bastante utilizada para designar os estudos de que trata este texto é “comunicação de massa". Em contraposição à indústria cultural, a comunicação de massa, na sua gênese, traduzia um certo viés democratizante, pois implicava a noção de que o conteúdo mediatizado resultava de uma escolha feita livremente pelas próprias "massas". Neste texto, trabalharei com estas duas expressões como sinônimas. Assim, tomarei a comunicação de massa ou indústria cultural, num sentido lato, o que incluirá bens, equipamentos (casas de cultura), especialistas que trabalham nesse tipo de equipamento, referências teóricas e ideológicas relativas a esse funcionamento, enfim, tudo que contribui para a produção de objetos semióticos (livros, filmes etc) difundidos num mercado determinado de circulação monetária ou estatal (Guattari \& Rolnik, 1986, p. 18).

O volume de produção teórico-prática que se pode enquadrar neste campo de estudo é muito grande. A partir da década de 50, mais especificamente, esta produção atinge um crescimento vertiginoso, sendo impossível acompanhar, sistematicamente, tudo o que surge de novo. No entanto, há um aspecto consensual entre os analistas desse campo que designa a indústria cultural como fruto da sociedade, inaugurada com a Revolução Industrial: a Sociedade Industrial. E por isso, para discutir os meios de comunicação de massa, é imprescindível que se discuta a sociedade industrial, cujas características marcam, indelevelmente, a comunicação de massa. Rocha (2000) sintetiza bem as características comuns à sociedade industrial e à indústria cultural: primeiro, a visão produtivista de mundo, enunciadora da máxima segundo a qual tudo em nossa cultura deve ser transformado em riqueza, tudo deve estar integrado à produção de mercadorias em geral (compartilhando da lógica frenética de produzir novas ondas de produtos, com aparências sempre mais novas, com taxas de transferência cada vez mais altas); depois, a dificuldade de conviver com a diferença, a tendência etnocidária ou "a destruição sistemática de modos de vida e pensamento" (p. 122) das culturas diferentes e, por fim, o individualismo como ideologia, que significa afirmar, também no campo cultural, o indivíduo como unidade social relevante.

Visão produtivista de mundo, tendência etnocidária e individualismo são parâmetros que ganham corpo com a sociedade industrial, mas permanecem e se complexificam nos tempos que correm, pois os avanços tecnológicos envolvidos na globalização potencializam o circuito de trocas, diversificam os produtos, colocam os habitantes do planeta em contato mais estreito com um maior número de manifestações culturais, veiculam a diferença, o contato mais direto com ela e multiplicam o potencial da mídia em afetar as qualidades culturais das populações. Conforme Hardt e Negri (2001), “... por certo existiram anteriormente numerosos mecanismos para moldar a opinião pública e a percepção pública da sociedade, mas a mídia contemporânea oferece instrumentos imensamente mais poderosos para essas tarefas" (p. 343).

\section{A Teorização Frankfutiana e a Indústria Cultural}

Os debates em torno da cultura afetada pelo boom dos meios de comunicação têm como referências históricas pioneiras os teóricos da Escola de Frankfurt. No bojo de suas críticas, mais especificamente das de Adorno, no campo da cultura, encontrava-se a preocupação com a homogeneização cultural e a desqualificação de certos símbolos da alta cultura através da indústria cultural.

Os teóricos de Frankfurt, assim como alguns autores atuais alinhados com o pensamento frankfurtiano, enfatizam o caráter de doutrinação político-ideológica da indústria cultural, falam, sobretudo, de seu serviço em favor da manutenção do status quo, e de uma economia baseada no consumo. Desta forma, a indústria cultural, ao mesmo tempo em que desvaloriza os produtos culturais através da homogeneização e da produção com fins meramente lucrativos, seria responsável pela despotencialização da capacidade crítica dos indivíduos, educando-os apenas para a conservação e o consumo.

Uma das principais críticas dos frankfurtianos no campo da cultura aponta uma tendência, nos meios de comunicação, à construção da homogeneidade cultural, em detrimento do particular e da diferença. Dessa forma, para os teóricos dessa linha, a singularidade dos indivíduos e as características culturais específicas de cada grupo são solapadas. Além disto, consideram que os media funcionariam como 
tradutores das produções de vanguarda, já que se apropriam do que poderia ser uma criação, um avanço cultural, transformando as obras e também as artes em mercadorias, despotencializadas enquanto inovação, a serem consumidas em larga escala. Mesmo que transmitam ao público produções da alta cultura, fazem-no de forma já “digerida”, resultando em conteúdos que não demandam nenhum esforço intelectual para a "fruição" da mensagem.

Os discursos alinhados com o pensamento frankfurtiano falam de modos de subjetivação quase totalmente capturados pela dominação da indústria cultural, em Adorno, ou pela "cultura afirmativa" burguesa, em Marcuse (1978). Em síntese, a discussão sobre os media é colocada sobre uma ótica eminentemente política, que trata de ideologias e de luta de classes.

"A indústria cultural é a integração deliberada, a partir do alto, de seus consumidores. Ela força a união dos domínios, separados há milênios, da arte superior e da arte inferior. Com o prejuízo de ambos. A arte superior se vê frustrada de sua seriedade pela especulação sobre o efeito; a arte inferior perde, através de sua domesticação civilizadora, o elemento de natureza resistente e rude, que lhe era inerente enquanto o controle social não era total. (...) as massas não são, então, o fator primeiro, mas um elemento secundário, um elemento de cálculo; acessório de maquinaria" (Adorno, 1975, p.288).

Os pensadores da Escola de Frankfurt viveram os efeitos do fordismo, que se apresentava como uma política de controle e gerência do trabalho, mas cujos efeitos sociais tornaram-se bem mais amplos. Afirma-se, com esses autores, que a expansão da produção capitalista - especialmente depois do impacto do fordismo e da gerência científica da produção - necessitou da construção de novos mercados e da "educação" das massas consumidoras para mercadorias - culturais ou não - massificadas e homogeneizadas. A lógica da mercadoria e da racionalidade instrumental invadia o consumo, as atividades de lazer, a arte e a cultura, de modo que a recepção cultural tornou-se condicionada pelo valor de troca, na mesma medida em que os valores e propósitos mais elevados da cultura sucumbiram.

A contribuição frankfurtiana para o estudo das formas de subjetivação frente aos meios de comunicação é extremamente significativa, principalmente quando se remetia à defesa da autonomia, da liberdade de escolha e da auto-afirmação humana, numa sociedade que sobrevivia carregada de inclinações totalitárias. Mas não parece suficiente para a apreensão e análise dos tempos que correm, tempos de muitos produtos culturais, de apregoamento de comportamentos fluidos e de apelos exacerbados às saídas individuais para o enfrentamento dos riscos e contingências do mundo.

O contexto global exige a reconfiguração do debate sobre a cultura e os meios de comunicação, ou sobre a indústria cultural. Nos discursos advindos de tempos de globalização, a discussão clássica sobre homogeneização versus diferenciação cultural é contemplada com outras perspectivas de análise, forjadas pelo encontro com a diferença cultural, com a estranheza e as velozes transformações geopolíticas. Em outros termos, com a globalização, novas análises se abrem para esta discussão.

\section{Meios de Comunicação de Massa no Contexto Global}

Um primeiro aspecto a ser considerado, no atual contexto, em relação à mundialização da cultura diz respeito às inovações tecnológicas. (Ortiz, 1994, Sevcenko, 2001). Entrando no século XXI, as dificuldades técnicas em relação à comunicação, que existiam antes, são cada vez mais irrelevantes e o planeta caminha para uma rede informacional cujas partes se encontram interligadas (Ortiz, 1994, p. 6263). Com os avanços tecnológicos - especialmente os da telemática e da microeletrônica - os meios de comunicação possibilitam, com extrema rapidez, um deslocamento que pode colocar a todos os que a eles tem acesso, em contato com o mundo.

A convivência contemporânea, possibilitada por esta época, indica uma verdadeira compressão espaço-temporal, em que as qualidades objetivas do espaço e do tempo se transformam, a ponto de nos forçarem a alterar, às vezes radicalmente, o modo como representamos o mundo para nós mesmos. Na realidade, a história do capitalismo tem se caracterizado por uma aceleração do ritmo de vida, e por uma permanente ultrapassagem das barreiras espaciais. No entanto, tais dinâmicas assumiram um ritmo tão célere no contexto da globalização, que "por vezes o mundo parece encolher sobre nós" (Harvey, 1994, p. 219). Os meios de comunicação contemporâneos têm uma intensa participação nesse processo. A TV, por exemplo, associada com a comunicação por satélite possibilita a experiência de uma enorme gama de imagens vindas de espaços distintos quase simultaneamente, encurtando as distâncias dos espaços do mundo.

O acúmulo de informações que uma população pode receber pelos atuais meios de comunicação de massa é de tal monta, que alguns autores - denominados de "integrados" por Eco (1976) - acreditam na positividade dos seus serviços para uma melhoria intelectual das massas e na contribuição que podem oferecer para um incremento da participação social. Mas as críticas às análises dos integrados são muitas e intensas, culminando com a idéia de que se a mídia elevou o volume de informações que as pessoas têm daquilo que se desenrola na sociedade, por outro lado, inibiu, na mesma proporção, a capacidade de converterem esse conhecimento em participação política e coletiva. Em seu clássico trabalho histórico, Sennett (1988) dispara “... os meios de comunicação de massa intensificam os padrões de silêncio que começaram a tomar forma nos teatros e salas de concerto do século passado (século XIX), intensificando a idéia do espectador destituído de corpo, uma testemunha passiva..." (p.346).

Fato é que os meios de comunicação possuem capacidades inimagináveis em outros momentos históricos como, por exemplo, a de empilhar imagens do passado e de outras épocas às atuais, re-apresentando tudo como uma "colagem coesa de fenômenos igualmente importantes e co-existentes" (Harvey, 1994, p. 63), e exigindo dos seus clientes uma per- 
cepção do tempo (da história) e do espaço (o meio onde vive) enquanto uma reserva interminável de eventos iguais.

Tal circunstância assume qualidades oníricas quando a indústria cultural de entretenimento constrói simulacros materiais dessas imagens, na forma de ambientes, eventos e espetáculos, em muitos aspectos, indistinguíveis dos originais (Harvey, 1994, p. 261-262).

A redução da vivência a uma série de presentes puros e não relacionados no tempo implica também que a experiência do presente se torna poderosa e arrasadoramente vívida, conforme assinalado por Jameson (1995). O caráter imediato dos eventos e a espetacularidade com que se revestem os fenômenos - de ordem política, científica, militar, dentre outras - tornam-se uma poderosa matéria prima para a mitificação das consciências, a ponto de Baudrillard (1995) afirmar que "comunicações de massa não nos fornecem a realidade, mas a vertigem da realidade" (p.24). Trata-se da "sociedade do espetáculo", precocemente enunciada por Debord (1997), concebida como um grande emaranhado de ilusões, sonhos e fantasias, cujo objetivo seria a opressão humana.

A velocidade que rege todo este processo - mesmo que consideremos, conforme Santos (2001), que somente algumas pessoas, firmas e instituições são altamente velozes, e são ainda em menor número as que utilizam todas as virtualidade técnicas das máquinas - é surpreendente, aderindo plenamente à imagem, cunhada por Sevcenko (2001), de um loop da montanha russa. Pode-se dizer, então, que a velocidade acelerada e crescente da técnica constitui-se numa especificidade das inovações do contexto global, o que significou a imposição mais universal e peremptória desse ritmo aos corpos, às relações sociais e a toda a produção humana.

Um outro aspecto a ser destacado refere-se à forma pela qual os meios de comunicação retratam o mundo do qual falam. Na tentativa de envolver sua platéia, os personagens na mídia e nas publicidades são apresentados como pessoas íntimas, companheiros próximos. Baudrillard (1995) nos fala dessa tentativa de estabelecer uma comunicação "personalizada", que invade a cotidianidade e Sodré (1981) analisa, com propriedade, este modo de interpelação direta, essa atmosfera de simpatia e de camaradagem, sobretudo televisivas, como sendo um elemento central para a naturalização do mundo apresentado pelas imagens.

Neste ambiente, as questões políticas tomam um caráter pessoal ou até passam desapercebidas, "como se, no mundo virtual do espetáculo, as discriminações seculares de classe e raça pudessem enfim ser redimidas" (Hamburger, 1998, p. 486). O clima de intimidade com que os conflitos nos são apresentados é de tal monta que a ordem do político passa a se organizar na ordem do psicológico e do individual (Sennett, 1988).

Diante deste quadro, alguns autores têm demonstrado preocupação quanto ao papel socializador (ou dessocializador) da comunicação de massa. Primeiramente, preocupam-se com o conformismo, a resignação política ou a passividade que estes meios parecem reforçar, como já discutido. Depois, alertam para o peso que a mídia tem tido na formação das novas gerações, na produção e reprodução da ordem simbólica, equiparando-se ou até superando os clássicos aparelhos ideológicos - família e escola, especialmente (Sodré, 1981, Martín-Barbero, 1987, Mancebo, 2000, Sennet, 1988).

Neste ponto da discussão, já é possível visualizar a existência de análises contraditórias e mesmo divergentes em relação aos efeitos dos meios de comunicação de massa sobre as populações. Primeiramente, há os que denunciam que os avanços tecnológicos das telecomunicações, o acesso direto e simultâneo de indivíduos disponibilizado por estes meios, promove o aparecimento de uma cultura global unificada, remetendo, assim, a uma homogeneização cultural. Nesta linha de argumentação vale a tese da convergência da cultura global, mediante a qual, há uma imposição crescente de uma certa universalização, pelo menos no sentido da unificação dos estilos de vida, símbolos culturais e formas transnacionais de convivência. A já consagrada expressão "mcdonaldização do mundo" - cunhada por Ritzer (1995), numa alusão aos preceitos da empresa transnacional de fast-food, baseada num modelo de produtividade e rápido escoamento de gêneros padronizados - é a metáfora central neste campo.

Mas também há análises, dentro da tradição da cultural theory - como Mike Featherstone, Robertson, Appadurai, Albrow, Lash, Urry e vários outros - que não compartilham da tese da inevitabilidade da homogeneização cultural e dos homens. Para eles, a globalização não imporia uma unificação cultural; a produção de símbolos culturais e de informações em massa não conduziria ao surgimento de algo semelhante a uma "cultura global". Afirmam, sem descartar a possibilidade de processos desiguais de imposição cultural, que o processo de globalização, mais do que permitir o aparecimento de uma cultura global unificada tende a propiciar um cenário para a expressão e expansão das diferenças. Assim, o conhecimento de culturas de nações distintas, promovido em larga escala pelos mass media, pode gerar efeitos diversos, como uma maior consciência da diversidade dos estilos de vida encontrados no mundo, a ampliação da compreensão da própria sociedade e cultura nas quais os indivíduos se encontram envolvidos e, até mesmo, movimentos de fechamento de grupos para reforçar identidades - étnicas, geopolíticas, de gêneros, dentre outras -, que se sentem ameaçadas, o que, neste caso, dificultaria a possibilidade de desenvolvimento de uma cultura global unificada.

Desse modo, tais autores procuram ir além daquelas concepções que admitem os estilos de vida e o consumo cultural como produtos totalmente manipulados de uma sociedade de massas, e também da concepção oposta, a de que os estilos de vida e cultura são espaços autônomos e lúdicos, isentos de determinações sociais.

Featherstone (1996), por exemplo, afirma que há processos de padronização em curso, que constroem e disseminam signos, onde o produto consumido carrega consigo uma imagem que, por sua vez, é composta de valores específicos, freqüentemente ligados a distinções econômicas e a frações de classe. Mas, se por este viés, há um movimento de 
homogeneização cultural, por outro, o autor se pergunta sobre a possibilidade da globalização também acentuar diferenças, localismos e a complexidade cultural, contrariando um prognóstico de inevitável integração ou homogeneização (Featherstone, 1996, Gómez 1999). No mesmo sentido de Featherstone, Wallerstein (1999) usa a metáfora de um campo de batalha (ideológica) para a apresentar a sua compreensão de cultura. Neste campo, ao contrário de uma produção estritamente imperialista, dominante e vertical - com efeitos de "não-resistência" e de apreensão das mensagem tal como se apresentam - o autor destaca as diferenças nacionais e locais como fatores centrais para a interpretação e decodificação das mensagens.

Neste sentido, mesmo que se fale em uma cultura global, a noção não aponta para uma homogeneidade ou uma cultura comum, mas para uma amplificação de pontos de vista, para o fortalecimento da noção de que estamos envolvidos diariamente numa série crescente de contatos culturais com outros, que ampliam o leque de definições conflitantes do mundo com as quais somos postos em contato. Com estas definições, o conflito passa a ser o centro das discussões, o que não significa tirar o poder político, econômico e militar de cena e declarar que na globalização as culturas podem se confrontar num campo de igualdade. Os fatores de majoritariedade são centrais na disputa cultural, na decisão das importações e exportações de produtos econômico-culturais, mas nem por isso se pode afirmar que há apenas um centro emanador de uma cultura a ser consumida passivamente em escala global. Bourdieu (1979) analisa, inclusive, a disseminação maximizada de signos para diferentes locais e culturas, através dos intermediários culturais, os administradores da nova mídia global, encarregados de transmitir e traduzir estes signos, de promover e popularizar ativamente estilos de vida, junto a públicos mais amplos. Mas tal consideração não implica a assunção da existência de um centro, guiando os entendimentos sobre o mundo, ou uma assimilação passiva daquilo que é difundido pelos intermediários culturais. Certamente, devem-se considerar os interesses e relações político-econômicas dos países e potências em jogo, quando se fala de comunicação e de censura, mas sem esquecer que, por outro lado, ocorre, também, a possibilidade de confronto com "interpretações" de mundo diversas.

Se nos teóricos frankfurtianos o prisma utilizado é de uma ideologia dominante que se sobrepõe às massas, para esta outra linhagem de autores há uma tentativa de compreender os estilos de vida, relacionando-os ao habitus das frações de classe. Assim, as análises devem buscar as formas diferenciadas de apropriação dos produtos culturais, os estilos de vida de grupos ou classes diversas e um maior entendimento da produção e consumo de signos distintivos de classes e grupos sociais.

Na realidade, se fixarmos nossos estudos nas operações realizadas pelos usuários da cultura, poderemos nos surpreender com as possibilidades de desvios que se abrem no uso dos produtos culturais. Tal foi a empreitada da pesquisa de Certeau (1994). Procurou distanciar-se da análise dos produtos culturais oferecidos pelo mercado dos bens, ou pelos intermediários culturais, para esboçar uma teoria das práticas cotidianas e com isto pôde aproximar-se das micro diferenças construídas nas experiências dos usuários, pôde ver diferenças onde tantos outros só viam obediência e uniformização.

Localizou produção cultural dos usuários, disseminada nas regiões definidas e ocupadas pelos sistemas televisivos, urbanísticos, comerciais, dentre outros, onde muitos outros estudiosos só viam fabricação. Mostrou-nos a necessidade de analisar a manipulação operada pelos praticantes que não fabricam as imagens, pois só assim é possível apreciar a diferença ou a semelhança entre a produção da imagem e a produção secundária, mas absolutamente fundamental, que se esconde nos processos de utilização cultural. Só assim é possível captar as margens de manobra nas quais os usuários exercem a sua "arte" e descobrir como é que uma sociedade inteira não se reduz a membros passivos de um controle permanente. É possível identificar, ao cabo, "que procedimentos populares (também 'minúsculos' e cotidianos) jogam com os mecanismos da disciplina e não se conformam com ela a não ser para alterá-los, enfim, que 'maneiras de fazer' formam a contrapartida, do lado dos consumidores (ou dominados?)" (Certeau, 1994, p. 41).

Para Certeau (1994), há uma criatividade das pessoas ordinárias, uma antidisciplina oculta num emaranhamento de manobras silenciosas e sutis, mas eficazes, através das quais se inventa um modo diverso de transitar pela panóplia de produtos culturais difundidos.

\section{Subjetividade, Identidades e Cultura Global}

Como se pode observar, há uma infinidade de análises que tentam dar conta do problema da cultura e de seus principais difusores, os meios de comunicação, no capitalismo e em seu momento atual de globalização. Em todos os discursos, implícita ou explicitamente, a produção das subjetividades é incluída no jogo de forças que se forja no campo cultural.

Pode-se afirmar que o encontro das subjetividades com a variedade de estimulações trazidas pelos meios de comunicação de massa tem por efeito povoá-las com uma miscelânea de forças de toda espécie, vindas de toda parte. Multiplicam-se os estados passíveis de se engendrar as subjetividades, pulverizam-se as performances, abalando a crença na estabilidade identitária. São diversas as metáforas construídas para designar os destinos contemporâneos das subjetividades, que apontam neste sentido. Bauman (2000) toma de Ernest Gellner o conceito de "homem modulado" numa alusão à mobília modulada que não possui um formato "certo" e predeterminado, mas um conjunto infinito de formas e expansões possíveis, "o homem modulado não tem perfil nem função predeterminados... é um homem com qualidades móveis, disponíveis e cambiáveis" (p. 161). Fala-se de "personalidade pastiche" ou de um "camaleonismo social", para caracterizar um homem que pega nacos e pedaços de identidade de quaisquer fontes disponíveis, erigindo-os em úteis ou indesejáveis, conforme a situação. 
Assim considerando, as velhas identidades, que por séculos apresentaram-se como capazes de estabilizar diversos aspectos do mundo social estariam, então, em declínio. $\mathrm{O}$ indivíduo moderno, que por caminhos diversos almejava uma unificação e harmonia subjetivas - ou que pelo menos acreditava nesta possibilidade -, surge na pós-modernidade com "identidades" fragmentadas, "descentradas", deslocadas ou fragmentadas. Em síntese, por essas imagens, o fim da figura moderna da subjetividade, pelo menos aquela construída em torno de uma referência identitária, estaria com seus dias contados. Os corpos abrigariam estados múltiplos, muitos seriam os recursos para a criação, os mundos possíveis e estaríamos entrando, por fim, numa época em que a criação individual e coletiva seria acelerada.

No entanto, a questão não é tão simples. A mesma globalização que intensifica as misturas e pulveriza as identidades até então localizadas, pode pôr em cena uma homogeneização das figuras da subjetividade. Deste modo, teríamos indivíduos homogeneamente globalizados, flexíveis e descartáveis, preparados para rapidamente se desalojarem e substituírem suas cartografias subjetivas e suas identidades locais. Os historiadores Prost e Vicent (1992) falamnos de um "conformismo emancipado" para se referir a um movimento contraditório por parte da mídia, que consiste em apregoar, a um só tempo, a autonomia/liberdade individuais, diante dos múltiplos modelos que disponibiliza, e o conformismo. Para esses autores, os sujeitos são estimulados à passividade e ao conformismo, tendo a crença de que estão participando ativamente das decisões sociais e dos seus próprios rumos.

Sob outro prisma de análise, poderíamos afirmar que o contato com o novo não implica, necessariamente, a abertura para o estranho, não garante a tolerância ao mal-estar que isto provoca e, muito menos, a solidariedade com o nãofamiliar. Pelo contrário, não é raro que a desestabilização exacerbada, aliada à manutenção da referência identitária, aponte para o risco de sentimentos de vazios de sentido e de valor. Não raro também, assiste-se a vivência de falta de objetivos, fracasso, despersonalização e loucura. Além disto, para os habitantes "modulados" da sociedade, a "inclusão", a sensação de pertencer a um lugar ou grupo é um grande problema: é sua preocupação diária ...estamos sempre e em toda a parte parcialmente desalojados e deslocados. Assim, pôr-se em contato com novas e múltiplas realidades, ao invés de desenvolver um movimento produtivo e inovador, desencadearia uma vivência traumática diante do desassossego trazido pela desestabilização. Como proteção diante da proliferação de estímulos e para impedir que eles atinjam a construção identitária, defesas são desenvolvidas, inclusive aquelas que podem anestesiar a própria criatividade dos corpos. Conforme Harvey (1994), em períodos de fragmentação e de insegurança, o desejo de valores estáveis pode ser - e tem sido - reacendido, fazendo surgir uma ênfase intensificada na autoridade das instituições básicas - a família, a religião, o Estado. Sua tese é a de que quanto maior a efemeridade, tanto maior pode se tornar a necessidade de se descobrir ou produzir algum tipo de verdade eterna onde se possa residir com tranqüilidade. Neste trajeto, com muita facilidade, os indivíduos enrijecem as identidades locais de gênero, étnicas, religiosas, raciais ou até nacionais, baseadas ou não em alguma versão essencialista da história e do passado, em alguma verdade imutável.

\section{Considerações Finais}

A globalização, como um fenômeno múltiplo e que contém em seu bojo a diversidade, pode levar a caminhos bem diversos, nos quais podemos encontrar, desde um apelo ao universalismo cultural, que remeteria a uma inclusão homogeneizadora, até diversos tipos de resistência a esse processo, com a formação de grupos identitários, movimentos xenófobos e até apropriações criativas desenvolvidas por grupos de cidadãos. Neste contexto, a intensidade e rapidez dos fluxos de informações, garantidas pelo avançado desenvolvimento tecnológico dos meios de comunicação, e que desempenham papel fundamental na revelação da existência de múltiplas culturas, levam sujeitos, grupos e comunidades a se depararem com outras e novas culturas, conduzem, fortuitamente, ao aparecimento de novas culturas, provocando, ainda, uma tolerância cada vez maior à diversidade, mas também podem balizar reações negativas de intolerância com essa mesma diversidade/alteridade.

Os discursos aqui apreciados inserem-se em análises que ensaiam problematizações e respostas face a estas novas demandas. No entanto, algumas armadilhas precisam ser evitadas neste percurso. Não se trata de encarar a cultura de massa como um complexo terreno da subversão e da contestação. Tal literatura é bastante comum, quando os autores tratam da cultura popular (autêntica, de resistência, revolucionária, no limite) em contraposição à cultura de massa (homogeneizadora, alienante e reacionária). Nestes discursos, percorre uma certa insistência em detectar subversão em toda parte da cultura popular ou, o que é pior, descambam, com facilidade, para a exaltação de banalidades culturais, que nada possuem em comum com uma criação de repercussões transformadoras. Assim, quando nos propomos a examinar os desvios operados pelos usuários, quando localizamos as "artes" minúsculas desenvolvidas no campo mesmo dos produtos culturais impostos, resta uma questão, uma outra encruzilhada: qualquer produto cultural é válido? As primeiras formas críticas de abordar a questão estavam à procura de "verdades duradouras sobre o mundo", mas tal caminho mostrou-se perigosamente elitista e, com facilidade, conduzia as mal-disfarçadas hierarquizações sócio-culturais: a verdadeira cultura, a verdadeira consciência ... O seu oposto, o relativismo multicultural, por seu turno, pode conduzir a uma aceitação pouco crítica dos padrões dos meios de comunicação de massa .

Desse modo o "local", a "região" e suas produções também não podem ser tomados como territórios possuidores de contornos, com características culturais afinadas e que se contraporiam ao processo de globalização. O conceito de cultura não está relacionado a uma localidade, como se cada grupo social possuísse sua própria cultura, delimitada em 
relação a outras. Pois se assim fosse, estaríamos supondo, como o faz o relativismo, que as culturas são totalidades, formas ou configurações plenas. É preciso, por fim, evitar a transformação da "noção lábil e ambígua de cultura na de uma ordem substancial e isolada das práticas políticas e econômicas, capaz de gerar por si mesma fatos sociais" (Sodré, 2001, p. 19), em outros termos, tomar a cultura como um mecanismo identificatório, logo, como uma orientação prática determinada, precisa, uma unidade paradigmática, pois assim a cultura se substancializa e deixa de ser processo e elaboração. Quando se fala hoje de cultura, não é mais possível fazer referência a uma imagem de uma totalidade coerente e coesa, fechada e auto-sustentatada, com partes claramente articuladas e intimamente entrelaçadas. Para se discutir a cultura no contexto global é preciso referir-se a um quadro de uma vasta matriz de possibilidades no qual incontáveis combinações e trocas não absolutamente coordenadas podem ser feitas e com efeito o são (Bauman, 2000, p. 155).

A teorização sobre as novas subjetividades, considerando a participação dos meios de comunicação de massa, deve passar, obviamente, pelos mesmos embates e ciladas presentes no campo da cultura: pelo contato com as diferenças, pelo jogo que se dá entre a apropriação de tendências homogeneizadoras e outras que tentam a singularização. Deve passar, também, pelo questionamento de referenciais identitários bastante cristalizados para reconhecer possibilidades outras de existência.

De modo análogo ao definido no campo cultural, podese afirmar, como síntese parcial, que não se trata de defender as identidades locais para combater a globalização cultural, nem da defesa de universais identitários como antídoto à fragmentação vivenciada. Trata-se de rever, criticamente, o processo global com todos os seus instrumentos midiáticos, por um lado, e a própria referência identitária como tábua de salvação, em prol de uma singularização e da possibilidade de reinventar a vida.

\section{Referências}

Adorno, T. (1975). A Indústria Cultural. Em G. Cohn (Org.), Comunicação e indústria cultural (pp.270-291). São Paulo: Ed. Companhia Nacional.

Baudrillard, J. (1995). A sociedade de consumo. Rio de Janeiro: Elfos Editora; Lisboa : Edições 70.

Bauman, Z. (2000). Em busca da política. Rio de Janeiro: Jorge Zahar Ed.

Bourdieu, P. (1979). La distinction: critique social du jugement. Paris : Edition de Minuit.

Certeau, M. (1994). A invenção do cotidiano 1: artes de fazer. 5.ed. Petrópolis: Vozes.

Cevasco, M.E. (2001). Prefácio. Em F. Jameson, A cultura do dinheiro (pp. 7-16). Petrópolis: Vozes.

Debord, G. (1997). A sociedade do espetáculo. Rio de Janeiro: Contraponto.

Eco, U. (1976). Apocalípticos e integrados. São Paulo: Editora Perspectiva.
Featherstone, M. (1996). A globalização da complexidade: pósmodernismo e cultura de consumo. Revista Brasileira de Ciências Sociais, 32, 105-124.

Gómez, J.M. (1999). Globalização da política: mitos, realidades e dilemas. Em P. Gentili (Org.), Globalização excludente: desigualdade, exclusão e democracia na nova ordem mundial (pp. 128-179). Petrópolis : Vozes; Buenos Aires : CLACSO.

Guattari, F. \& Rolnik, S. (1986). Cartografias do desejo. Petrópolis: Vozes.

Hamburger, E. (1998). Diluindo fronteiras: a televisão e as novelas no cotidiano. Em L.M. Schwarz (Org.), História da vida privada no Brasil 5: contrastes da intimidade contemporânea (pp. 470-489). São Paulo: Companhia das letras.

Hardt, M. \& Negri, A. (2001). Império. Rio de Janeiro: Record.

Harvey, D. (1994). Condição pós-moderna. São Paulo: Edições Loyola.

Jameson, F. (1995). Pós-modernismo e sociedade de consumo. Novos Estudos CEBRAP, 12, 16-26.

Jameson, F. (2001). A cultura do dinheiro. Petrópolis: Vozes.

Mancebo, D. (2000). Globalização e efeitos de subjetivação. Logos, 7, 58-62.

Marcuse, H. (1978). A ideologia da sociedade industrial: o homem unidimensional. 6.ed. Rio de Janeiro: Zahar Editores.

Martín-Barbero, J. (1987). De los medios a las mediaciones: communicación, cultura y hegemonía. México: Ediciones G. Gili.

Ortiz, R. (1994). Mundialização e cultura. São Paulo: Brasiliense.

Prost, A. \& Vicent, G. (Orgs.). (1992). História da vida privada 5: da Primeira Guerra aos nossos dias. São Paulo: Companhia das Letras.

Ritzer, G. (1995). The macdonaldization of society. Thousands Oaks: Pine Forge.

Rocha, E. (1995). A sociedade do sonho: comunicação, cultura e consumo. 2.ed. Rio de Janeiro: Mauad Ed.

Santos, M. (2001). Por uma outra globalização. Rio de Janeiro: Record.

Sennett, R. (1988). O declínio do homem público: as tiranias da intimidade. São Paulo: Companhia das Letras.

Sevcenko, N. (2001). A corrida para o século 21. São Paulo: Companhia das Letras.

Sodré, M. (1981). O monopólio da fala, função e linguagem da televisão no Brasil. Petrópolis: Vozes.

Sodré, M. (2001). A mascarada multiculturalista. Em N. Vilaça \& F. Góes (Orgs.), Nas fronteiras do contemporâneo (pp. 15-22). Rio de Janeiro: Mauad.

Wallerstein, I. (1999). A cultura como campo de batalha ideológico do sistema mundial moderno. Em M. Featherstone (Org.), Cultura global: nacionalismo, globalização e modernidade (pp. 75-79). 3. ed. Petrópolis: Vozes.

Recebido em 23/04/2002

Primeira decisão editorial em 17/07/2002

Versão final em 10.08.2002

Aceito em 12/09/2002 